\title{
AS CONDIÇÕES DE PRODUÇÃO QUE POSSIBILITARAM A EMERGÊNCIA DOS DISCURSOS SOBRE O CAMPO E A CIDADE EM O CACHORRO E O LOBO
}

\begin{abstract}
Joselia Santos da Silva ${ }^{1}$
Maria Neuma Mascarenhas Paes ${ }^{2}$

Resumo: Neste trabalho, buscamos descrever e analisar as relações e conflitos entre campo e cidade nos discursos presentes na obra de Antonio Torres, $O$ cachorro e $o$ lobo. Para embasar o trabalho, recorremos aos procedimentos teóricos da Análise do discurso, a partir de Orlandi (1999), Pêcheux (1997), Fernandes (2007), Indursky (2008) e Brandão (2013). E, para discutir o campo e a cidade, nos valemos das contribuições teóricas de Williams (1973), Wirth (1938) e Bagli (2010). A análise se constituiu na descrição e interpretação dos discursos, mas levando-se em consideração os aspectos sociológicos e literários da obra. Ressalta-se que, dentre os procedimentos teóricos da Análise do Discurso, trabalhamos as condições de produção que possibilitem a emergência dos discursos, as formações discursivas que permitem verificar aquilo que pode e deve ser dito pelos sujeitos em determinado momento e as formações ideológicas que constituem os sujeitos e consequentemente as formações discursivas; dentre os aspectos sociológicos e literários destacamos as discussões entre campo e cidade e a forma como o texto é abordado.
\end{abstract}

Palavras-chave: Campo versus Cidade. Conflitos e relações. Condições de produção. Formação discursiva.

\section{PRODUCTION OF CONDITIONS THAT ENABLES THE URGENT DISCUSSION ABOUT FIELD AND CITY IN THE DOG AND THE WOLF}

\begin{abstract}
In this work, we searched to describe and analyze the conflicts and relations between field and city that are addressed in the work of Antônio Torres, The dog and the wolf. To base our work, we appealed to the theoretical procedures of analyzing and discussing of "Orlandi (1999), Pêcheux (1997), Fernandes (2007), Indursky (2008) and Brandão (2013). To discuss about the field and the city we also counted on the theoretic contributions of William (1973), Wirth (1938) and Bagli (2010). The analyses involves the description and interpretation of arguments, but also taking in consideration the sociological and literal aspects of the work. Emphasizing that, in the process of this theoretic and analytical procedure, we worked the production conditions that enabled the urgency of these arguments, the discursive formations that allowed the verifications of what should and can be said by the subjects at a determined moment. As well as the ideological formations that create the subject and consequently the discursive formations. About the sociological and literary aspects, we emphasized the arguments between the field and the city as well as the form in which it is addressed in the text.
\end{abstract}

Keywords: Field and City. Conflicts and relationeships. Production of Conditions. Discursive Formation.

\footnotetext{
${ }^{1}$ Licenciada em Letras-Língua Portuguesa e Literaturas pela Universidade do Estado da Bahia-UNEB. Aluna da Pós-Graduação em Crítica Cultural (Pós-Crítica), da UNEB. E-mail: josy.ssilva@hotmail.com

2 Professora Doutora da UNEB/Campus II. Pesquisadora do Grupo de Estudos em Resiliência, Educação e Linguagem (GEREL). E-mail: mpaes@uneb.br
}

Pontos de Interrogaçăo, v. 6, n. 2, jul.-dez., p. 31-48, 2016. 


\section{Introdução}

A Análise do Discurso, área do conhecimento da qual nos valemos para desenvolver as análises deste trabalho, surgiu na França na década de sessenta com o objetivo de estudar o discurso. Pêcheux ([969] 1975), um dos fundadores da Análise do Discurso de linha francesa, mostrou grande interesse pelo desenvolvimento dos pressupostos teóricos da disciplina, buscando, assim, romper com o método de leitura baseado na interpretação de conteúdos e sugerir a identificação dos processos de produção de sentido nos discursos, já que a linguística imersa no método estruturalista, corrente na época, não contemplava tais aspectos.

A primeira fase da Análise do Discurso foi marcada pelo programa Análise Automática do Discurso (AAD69), por meio do qual se buscava compreender a língua em seu funcionamento. Este programa foi desenvolvido depois de se observar as práticas de leituras que tentavam compreender os textos através de questionamentos feitos ao próprio texto. Na tentativa de mudar essa prática, Pêcheux ([1969] 1975) instaura um novo mecanismo de leitura baseado na teoria dos processos discursivos, que leva em conta a exterioridade dos textos, as condições que tornavam possível a produção dos mesmos. É nesse momento que Pêcheux elabora o conceito de condições de produção (doravente $\mathrm{CP}$ ) para explicar os processos de produção de um discurso. A partir daí, o conceito de CP tornou-se fundamental, uma vez que, na análise de um corpus ou de um texto, devemos levar em consideração a exterioridade, o momento de suas produções, porque a emergência dos discursos irá de uma forma ou de outra interferir na constituição de sentidos.

No desenvolvimento das análises, partimos dos pressupostos teóricos e metodológicos da Análise do Discurso, na perspectiva francesa. De modo que, a princípio, buscamos entender os fenômenos linguísticos os quais permitiram as interpretações de fragmentos representativos que constam na obra. Entre os procedimentos teóricos da Análise do Discurso, trabalhamos com as CP dos discursos, para entender as Formações Imaginárias dos sujeitos envolvidos na interlocução, a contextualização da obra (o referente), que possibilitou a emergência e a memória dos discursos. No que diz respeito às formações discursivas (doravente FD), verificamos aquilo que pode e deve ser 
dito pelo sujeito, em um determinado momento, ou seja, se ele superpõe ou contrapõe à FD dominante, que está de acordo com a Formação Ideológica.

Um dos conceitos essenciais que percorre a presente discussão são as $\mathrm{CP}$, que, em seu sentido amplo, correspondem ao contexto sócio-históricoideológico do discurso e, em sentido estrito, incluem as circunstâncias da enunciação: é o contexto imediato. As $\mathrm{CP}$, portanto, envolvem a língua comum aos interlocutores e a exterioridade linguística constituintes dos discursos, assim as definem Orlandi (1999).

A obra que se analisa, neste trabalho, faz parte da trilogia que se inicia com Essa terra e se finda com Pelo fundo da agulha. Em O cachorro e o lobo (obra intermediária), o autor institui como narrador/personagem Totonhim, que migrou para São Paulo em busca de sobrevivência e voltou a sua terra natal depois de vinte anos afastado. Na narrativa, ao regressar para o povoado no interior da Bahia, Junco, hoje, Sátiro Dias, Totonhim faz uma longa viagem ao passado, recontando a história de sua família naquele lugar, relembrando as pessoas que compunham aquele cenário, seus sonhos e, ao mesmo tempo, mostrando como o lugar havia adquirido certas características da vida urbana. Enfim, expõe as formações imaginárias de um sujeito que se constituiu no meio rural e, de forma intercambiável, procura se ajustar ao meio urbano, assumindo os lugares que lhe são determinados, mas não consegue se desvencilhar das lembranças de um passado que, de forma subjetiva, o instituiu como sujeito de discurso.

Com o desenvolvimento das cidades, o campo, que antes era de fundamental importância para o homem, lugar onde se mantinha uma relação íntima com a terra, transforma-se em um espaço menos prestigiado, visto que a urbanização com suas tecnologias torna-se dominante. O campo era marcado como território de contato com a natureza e meio de sustento das pessoas. Mas esses valores se perderam, tendo em vista que os aspectos urbanos passam a predominar perante o modo de vida no campo.

As diferenças entre o campo e a cidade são bastante amplas e podem aparecer sob diversas formas, tanto na ficção quanto nas narrativas históricas. Em $O$ cachorro e o lobo, as divergências encontradas entre o urbano e o rural são de certo modo complexas e notavelmente relacionadas 
ao cotidiano de nossa sociedade. Sendo assim, o presente trabalho justifica-se por suscitar uma reflexão acerca do urbano e do rural dentro e fora da literatura, levando-se em consideração os aspectos que fizeram emergir as diferenças entre esses espaços. Em vista disso, é significativo falar sobre a predominância do ambiente urbano na sociedade e seu retrato na literatura, que carrega em si divisões em diversos segmentos entre as quais está a fronteira ou "abismo" que separa o meio rural do meio urbano.

Partindo do que foi introduzido até aqui, passamos então a análise de $O$ cachorro e o lobo, obra de Antonio Torres. No referido romance, Antônio Torres apresenta um cenário peculiar como alguém que conhece o lugar, para desenvolver a narrativa literária e, ao mesmo tempo, torná-la um acontecimento de linguagem, no qual podemos identificar os processos discursivos. O espaço que constitui o cenário da obra é o interior da Bahia. Na narrativa, entendemos que autor e personagens se confundem, pois na constituição do sujeito de discurso, o autor assume uma posição sujeito e se mostra, de forma subjetiva, por meio dos personagens.

Encontram-se materializadas, no romance, questões sociais como o êxodo rural dos nordestinos, principalmente, a partir da década de 1940, o desenvolvimento urbano e o consequente atraso do campo. Destacam-se, portanto, as relações que se estabelecem entre o espaço urbano e o espaço rural. O primeiro, em pleno desenvolvimento, o segundo, estagnado no tempo e no espaço. Questões como essas estão ligadas a um contexto histórico específico que possibilitou a produção de $O$ cachorro e o lobo.

Nesse sentido, podemos pensar como a literatura se relaciona com a história e como se apropria dessa, recriando-a. Como afirma Borges (2010), a literatura se constitui como uma forma de representação social e histórica, como testemunha de uma época. Configurando-se como uma forma de representar a realidade social, cultural ou histórica, a literatura traz em si o cruzamento entre o individual e o coletivo, pois, ao falar de uma coletividade, o autor está também se inserindo nela. Desse modo, o autor ao produzir as representações do real está dialogando com a realidade na qual se insere. É o caso de $O$ cachorro e o lobo, em que Antonio Torres, enquanto autor, se 
constitui como sujeito de discurso para se subjetivar em uma realidade coletiva da qual faz parte e conhece tão bem.

A ocorrência desse processo é possível, porque a literatura com seu jogo de linguagem é capaz de registrar acontecimentos de uma época, de uma sociedade, trazendo para nós, leitores, a possibilidade de acessar informações muitas vezes camufladas pelas narrativas históricas. Dessa maneira, a ficção, ao representar a realidade sociocultural de um lugar e de um tempo, o faz com um novo direcionamento, lançando um novo olhar e novas interpretações sobre a realidade representada.

Desse modo, a literatura se constitui como um poderoso instrumento de representação do real, podendo assumir uma posição de denúncia ou de testemunha dos fatos históricos pertencentes a uma época e lugares determinados. É, portanto, a representação do real que permite a identificação das materialidades discursivas, não como dados, mas como evidências.

Nessa perspectiva, consideramos que a literatura é carregada de intencionalidade e de discursividade, ela traz em suas representações reflexões acerca do conteúdo que carrega, convidando o leitor para, em um gesto de interpretação, refletir sobre uma determinada realidade.

Em O cachorro e o lobo, entendemos que acontece algo semelhante, Antônio Torres, no exercício da função autor, ao mesmo tempo que revisita os lugares perdidos na memória, convida o leitor para fazer o percurso com ele. Nesse sentido, o romance em questão traz esse lugar para o espaço discursivo, resgatando-o do esquecimento e dando voz aos personagens. Enfim, o autor consegue, em $O$ cachorro e o lobo, representar e testemunhar a realidade de uma época, transformando a obra em um acontecimento de linguagem.

É neste sentido que vamos analisar a obra, em uma perspectiva que vai muito além do estudo da língua, dos aspectos gramaticais, das regras que regem o seu uso, das teorias literárias. Iremos considerar também os elementos extralinguísticos que estão intrinsecamente ligados à produção dos discursos, tendo em vista que cada sujeito está situado em um tempo e um espaço específico, possui valores, ideologias e visão de mundo próprias. Tudo isso para chegarmos à interpretação. Faz-se necessário, quando falamos em 
discurso, ampliar nossa visão para além dos aspectos linguísticos, já que as crenças, os valores, a ideologia que o sujeito carrega se fará presente em seu discurso, "é por isso que dizemos que não há discurso neutro, todo discurso produz sentidos que expressam as posições sociais, culturais, ideológicas dos sujeitos da linguagem" (BRANDÃO, 2013, p. 3).

Nesse sentido, as CP se constituem como um elemento fundamental para a Análise do Discurso, que, de acordo com Brandão (2013, p. 6), “pode ser definida como o conjunto dos elementos que cerca a produção de um discurso: o contexto histórico-social, os interlocutores, o lugar de onde falam, a imagem que fazem de si, do outro e do assunto de que estão tratando". Assim, tendo em vista que os discursos não são soltos, vazios, mas contextualizados, na análise, é preciso levar em consideração o contexto de produção. É preciso identificar quem produz o discurso (o sujeito destinador), a quem é dirigido (o sujeito destinatário), a situação (os aspectos sociais, históricos e geográficos que envolvem tal discurso).

Enfim, na análise, devemos levar em conta as CP que sustentam a construção dos discursos. Não podemos perder de vista que, na constituição de sentidos, todo dizer tem uma relação com sua exterioridade, com o que é dito em outro momento, em um espaço determinado. É preciso considerar que nas "condições de produção em sentido estrito temos as circunstâncias da enunciação: é o contexto imediato. E se as considerarmos em sentido amplo, as condições de produção incluem o contexto sócio-histórico, ideológico" (ORLANDI, 2002, p. 30).

De acordo com Pêcheux (1975), citado por Lagazzi (1988), as CP correspondem ao "efeito das relações de lugar no interior das quais se encontra inscrito o sujeito". Além disso, quando falamos em $\mathrm{CP}$, nos remetemos à situação concreta (ao momento da enunciação), ao locutor e ao interlocutor (aos sujeitos de discurso). Assim, de acordo com Fernandes (2007, p. 28), o discurso tem existência na exterioridade do linguístico, no social, é marcado sócio-histórico-ideologicamente.

Nesse aspecto, toda análise requer atenção, já que, para se analisar os discursos, é necessário levar em consideração todos os processos que os constituem e que lhes conferem sentidos, pois é inviável a compreensão dos 
processos discursivos pelos objetos simbólicos, se não houver remissão ao que existe no sentido já lá.

Em sentido estrito, temos, portanto, o contexto imediato, o momento da formulação da obra funcionando da seguinte forma, de um lado, Antonio Torres, enquanto autor, destinador dos discursos, constitui-se em sujeito de discurso, a quem vamos chamar de sujeito (A), por outro lado, temos seu interlocutor, o público leitor, que chamaremos de sujeito (B). Acrescentase ao esquema de construção dos sentidos o referente (momento em que a obra foi escrita), na última metade do século XX. O cachorro e o lobo surge, tendo como personagem aquele que, em Essa terra, foi testemunha da partida do irmão mais velho (Nelo) para São Paulo e a volta do mesmo, que, não resistindo ao peso do fracasso, de ter retornado sem melhores condições de vida, acabou cometendo suicídio. O cachorro e o lobo retrata um momento em que o processo de migração era intenso e a cidade grande estava em destaque, o que fez as pessoas do interior partirem em busca de sobrevivência.

Em sentido amplo, temos os aspectos sociais, históricos e ideológicos. Os discursos são produzidos de acordo com os lugares socioideológicos que os sujeitos ocupam e, por isso, se dá a produção de um discurso e não de outro. Dessa forma, o romance posto em análise reúne discursos condizentes com o lugar que o sujeito enunciador ocupa. Nesse caso, Antônio Torres, na função autor, elege como sujeito discursivo o narrador (Totonhim) e, por meio dele, vai falar de dois mundos antagônicos que torna o sujeito dividido. Primeiro, Junco, interior onde nasceu. Segundo, São Paulo, onde passou a viver.

O sujeito destinador, que vamos chamar de (A), para construir um discurso ambientado no espaço rural, revisita suas Formações Imaginárias, pondo de forma representada as relações cotidianas de um lugar que o constituiu como sujeito desse discurso. Isso fica evidente quando o sujeito (A) traz para seu discurso os elementos regionais, destacando acontecimentos, como por exemplo, o êxodo rural dos nordestinos para o sul do país, entre outras representações. Na heterogeneidade dos discursos, o autor aborda também a cidade grande, explicitando uma FD dominante que conhece, sabe como funciona e por isso questiona. 
Daí, podermos dizer que o sujeito (A) se constitui como um sujeito discursivo e, como tal, revela em seu discurso o lugar social a que pertence e um conjunto de outras vozes presente em sua fala. Desse modo,“[... o sujeito não é homogêneo, seu discurso constitui-se do entrecruzamento de diferentes discursos, de discursos em oposição, que se negam e se contradizem" (FERNANDES, 2007, p. 36). O sujeito é, pois, heterogêneo, já que, na sua voz se faz presente um conjunto de diferentes vozes. Tendo em vista que o sujeito quando produz seu discurso o faz com base em outros discursos produzidos em outros lugares, vale ressaltar que é através da retomada desses discursos pré-construídos que novos discursos são produzidos. Entra em jogo aí o interdiscurso, nele encontram-se todos os dizeres existentes sobre um determinado saber.

É pensando no interdiscurso que entendemos que nossos dizeres, nossas palavras só fazem sentido porque já existem, porque já possuem sentido. Todo discurso é produzido se sustentando em uma memória, mesmo que o sujeito não se dê conta disso. Dito de outra forma, todo discurso dialoga com outros discursos e é nesse diálogo que novos discursos vão sendo construídos. Sendo assim, Antonio Torres enquanto sujeito de discurso tem sua produção discursiva alimentada por uma rede de discursos, os quais aciona e retoma para sustentar o seu dizer. Assim, os discursos que revelam conflitos entre campo e cidade em $O$ cachorro e o lobo são alimentados por uma rede discursiva produzida por outras vozes em outros lugares.

\footnotetext{
Daqui pra frente preciso controlar a minha impaciência diante da fala arrastada desse povo, da sua prosa demorada, comprida, interminável. E procurar entender o que há de bom nisso. Vai ver, eles é que estão certos. Fazem esse velho mundo parecer um pouquinho mais humano. O problema é que acabo não tendo saco para tanta falta de pressa. (TORRES, 1998, p. 152)
}

Na citação acima, retirada de $O$ cachorro e o lobo, o sujeito de discurso, narrador/personagem, remete-se a um discurso construído anteriormente em que se diz que a cidade é guiada pela intensa movimentação e pela rapidez do tempo, enquanto no campo o tempo corre devagar, seguindo a lógica dos acontecimentos. Evidencia-se, portanto, no 
discurso do sujeito de discurso que, na cidade, os homens acompanham a velocidade das máquinas e, no campo, eles seguem o ritmo natural da vida:

No urbano, o cotidiano é construído sobre um tempo mecânico. As formas como as pessoas se apropriam do tempo e dele se utilizam não são compassadas pelas mudanças naturais. Ritmo do tempo segue a velocidade da mobilidade excessiva dos processos de produção, circulação, troca e consumo de mercadorias. (BAGLI, 2010, p. 83)

Ainda com base nesses discursos produzidos em outros lugares e momentos, o enunciador da obra em questão leva para seu discurso outra voz que fala do processo intenso de urbanização que está indo de encontro com os espaços rurais.

O lugar agora está uma gracinha. Dá gosto de ver. Tem luz elétrica noite e dia, água encanada, televisão de montão, banca de jornais, dois ginásios, dois hospitais, supermercado, carro a dar com o pau e, pasme, até uma biblioteca pública! (TORRES, 1998, p. 12)

O efeito de sentidos que o enunciador produz no trecho supracitado nos leva a pensar que o interior ao qual o mesmo se refere está ganhando características urbanas e até mesmo perdendo seu caráter rural. A esse respeito Bagli (2010, p. 95) afirma:

[...] Seguindo essa reflexão, o rural para se manter rural teria que está destituído de todo e qualquer tipo de tecnologia criada para facilitar a vida das pessoas. Isso significaria dizer que a condição de ruralidade seria dada pela ausência total de tecnologias e pela rusticidade.

Segundo a autora, se considerarmos que a presença de tecnologias confere a um ambiente um status urbano estaremos admitindo que o campo para ser considerado campo deve ser desprovido de qualquer tipo de inovação tecnológica.

Outro discurso está presente no discurso do enunciador em $O$ cachorro e o lobo. Aquele que diz que a cidade é guiada pela lógica da produção 
e do capital e, embora ela concentre um grande número de pessoas, não consegue oferecer oportunidades suficientes ou ainda acaba excluindo aqueles que não conseguem se incorporar à lógica do capitalismo, ou melhor, não conseguem ser produtivos a ele.

Pensemos, sobretudo nas pessoas, tanto naquelas que são atraídas pelo urbano (via processo migratório), quanto naquelas que são subjugadas ("engolidos" via processo de expansão) à sua lógica. O urbano concentra pessoas, mas não oferece oportunidades a todos (BAGLI, 2010, p. 101).

Em O cachorro e o lobo, o personagem Nelo entra em jogo para trazer à tona justamente esses discursos que o sujeito enunciador retoma. Nelo foi para São Paulo em busca de melhores condições de sobrevivência, no entanto não consegue ser incorporado ao grande sistema produtivo e, por isso, é descartado pelo mesmo, retornando ao seu lugar de origem com o peso do fracasso que o fez colocar fim na própria vida.

[...] Primeiro uma conversa com meu irmão Nelo, aqui nesta cozinha, no dia em que ele chegou de São Paulo, muito bem embalado num terno de casimira, sapatos de duas cores, a boca cheia de dentes de ouro, um relógio brilhando mais do que a luz do dia, um radio de pilha faladorzinho como um corno, e nem um tostão furado nos bolsos - o que só fui ficar sabendo quando já era tarde demais para fazer alguma coisa (TORRES, 1998, p. 39).

Após a leitura de $O$ cachorro e o lobo, podemos constatar que o romance tem marcas autobiográficas, o que nos leva a inferir que o sujeito (A), ao assumir a função de escritor, posição essa munida de poder social, utiliza os recursos literários para falar de uma identidade brasileira da qual faz parte, para dar voz ao lugar que é colocado à margem da história e combater o apagamento, devolvendo, pois, a importância de sua existência. Para isso, o sujeito (A) produz seu discurso com base em crenças e valores que carrega. $\mathrm{O}$ discurso é, pois, oriundo do espaço socioideológico que o sujeito (A) ocupa, de outros discursos que atravessam a formulação de forma interdiscursiva. 
[...] o sujeito, ao mostrar-se, inscreve-se em um espaço socioideológico e não em outros, enuncia a partir dessa inscrição; de sua voz, emanam discursos, cujas existências encontram-se na exterioridade das estruturas linguísticas enunciadas (FERNANDES, 2007, p. 28).

Dessa maneira, o sujeito (A) se apropria de uma linguagem intrínseca ao espaço geográfico que está dando ênfase em seu discurso e, assim, atinge o público leitor, o sujeito (B) que poderá aderir ou não os sentidos advindos do discurso do sujeito (A).

O espaço geográfico onde ocorre a narrativa, nos é apresentado como um povoado simples, mas com sonhos enraizados na memória de seu povo. Como sendo um lugar situado no interior da Bahia, Junco não tinha muitas possibilidades de crescimento, era, desse modo, caracterizado pelo seu atraso, pela insuficiência de recursos econômicos que garantissem a sobrevivência do seu povo. Em vista disso, as pessoas do lugar iam embora para São Paulo, em busca de melhores condições de vida. O sonho do Junco era confiado a essas pessoas, acreditando que elas voltariam um dia com riqueza e sucesso, trazendo a prova de que a cidade grande é a fonte das realizações.

Percebemos, assim, que $O$ cachorro e o lobo é constituído por um discurso complexo de crítica da predominância da cidade e reconhecimento da precariedade da vida no interior. Isso porque o romance é marcado pelo movimento de migração para os grandes centros urbanos do sul do Brasil, muito comum na segunda metade do século XX.

Fica evidenciado nos discursos que a cidade grande, lugar dos avanços tecnológicos, capaz de abrigar grande número de pessoas, é uma ilusão. Não é o centro das realizações e possibilidades, pois nem todos conseguem melhorar de vida e adquirir sucesso imediato. Por outro lado, o interior é um lugar de atraso, sem possibilidades, e o destino daqueles que aí moram será a migração, e mesmo aqueles que não partiram ficaram à espera dos que foram para cidade, na esperança de que a civilização dos centros urbanos iria chegar para o interior. 
[...] Cadê o povo dessa terra? Morreu de sede? Foi devorado pelo sol? Onde está todo mundo? Em Alagoinhas, Feira de Santana, Salvador, Ilhéus, Itabuna, no Sul do cacau, na fuzarca do Rio de Janeiro, nos poderes de Brasília, nos garimpos do Pará, nas fazendas do Mato Grosso, nos rios do Amazonas, no trafico de Rondônia, nas terras verdes de São Paulo-Paraná, nos pampas do Rio Grande do Sul? [...] (TORRES, 1998, p. 78).

Assim, as vozes, os discursos que estão presentes no romance nos chamam a atenção para a realidade do interior, para o destino dos nordestinos, que era partir para outras regiões do país em busca de uma vida melhor. Desse modo, o sujeito enunciador através desses discursos mostra, pois, uma atitude de tornar explícito a imagem do lugar de onde fala e do qual fala. O sujeito (A) se situa como alguém que tem suas raízes no pequeno povoado do Junco e que, passando um longo tempo distante, se encontra dividido entre o mesmo e a cidade de São Paulo, onde até então estava estabelecido. Assim, ao acionar a memória o sujeito de discurso, através do narrador/personagem, faz um recorte dos acontecimentos que se passaram em Junco, relatando, principalmente, o suicídio de Nelo como exemplo de fracasso daquele que foi para São Paulo e retornou sem nada.

Além disso, através da ficção, o escritor Antonio Torres, enquanto sujeito do discurso, consegue dar voz ao interior que luta pela sobrevivência em face da invisibilização pela sociedade que enaltece os meios urbanos devido ao desenvolvimento industrial e pelo capitalismo que atrai e produz homens cada vez mais alinhados ao seu ritmo de crescimento.

Em $O$ cachorro e o lobo, podemos observar claramente a presença da cidade e do campo como espaços divergentes e que se encontram em constantes conflitos. O campo é apresentado como lugar de pessoas humildes que possuem e cultivam seus costumes, sua cultura, os modos de viver, de pensar sobre o mundo e agir sobre o mesmo. Diferente do espaço rural, a cidade possui outros valores, cultura e modos de vida bastante distintos daquele. A cidade na referida obra invade o campo com sua bagagem de valores e com seu caráter de detentora da civilização, deixando explícito para nós leitores os contrastes entre ambos os espaços. Isto fica claro quando o enunciador fala dos modos de vida do povo do Junco em comparação com os 
costumes urbanos e a atração que a cidade despertava nos moradores daquele lugar.

Em se tratando das relações sociais urbanas, constatamos, a partir da narrativa, que as pessoas da cidade fazem contato entre si de forma bastante impessoal, ou seja, não possui uma relação íntima ou uma proximidade significativa. Em síntese, as relações sociais entre indivíduos da cidade tendem a serem mais fechadas e pragmáticas.

Os contatos da cidade podem ser face a face, mas são, não obstante, impessoais, superficiais, transitórios e segmentários. A reserva, a indiferença e o ar blasé que os habitantes da cidade manifestam em suas relações podem, pois, ser encarados como instrumentos para se imunizarem contra exigências pessoais e expectativas de outros (WIRTH, 1938, p. 109).

Fica claro então que as pessoas do campo tendem a ser mais próximas e manterem uma relação social íntima, mais segura, ao contrário das pessoas da cidade, que, na velocidade do dia a dia, pouco se falam ou se olham por estarem sempre ocupadas e apressadas.

[...] Afinal, venho de uma cidade onde ninguém tem tempo a perder com uma história que não possa ser resumida assim:

- Oi, tudo bem?

-Tudo bem.

$\mathrm{Ou}$ :

- E aí, como vão as coisas?

Se você começa a explicar, o outro diz:

-Depois a gente se fala. Liga pra mim, tá? (TORRES, 1998, p. 67).

Vimos, no trecho supracitado como o enunciador da obra trata das relações sociais urbanas já mencionadas nesta discussão. Este é um aspecto de divergência entre campo e cidade revelada na obra. Embora a cidade seja tão idealizada, ela também possui aspectos negativos, como explicita Williams (1973, p. 11) ao dizer que: "também constelaram-se poderosas associações negativas: a cidade como lugar de barulho, mundanidade e ambição". Esse 
aspecto negativo da cidade por notável que seja não irá superar a predominância e muito menos o seu prestígio face ao campo. É preciso considerar que o campo possui aspectos positivos e negativos, o primeiro, refere-se ao seu caráter de harmonia, tranquilidade, o segundo, diz respeito ao seu atraso, inexistência de saberes sistematizados, etc. A respeito disso, Williams (1973, p. 11) fala que "o campo passou a ser associado a uma forma natural de vida - de paz, inocência e virtudes simples". Por outro lado o mesmo menciona o campo "como lugar de atraso, ignorância e limitação" (WILLIAMS, 1973, p. 11).

No tocante às diferenças entre campo e cidade no romance, o campo apresenta-se como um lugar simples, cujos moradores possuem as mesmas características. Além disso, o campo, em O Cachorro e o Lobo, mostra-se como um espaço isolado, longe da civilização da cidade. Em contraste com o rural, a cidade se configura como o ambiente das grandes civilizações, o lugar do conhecimento e informações valorizadas (temos aqui uma Formação Ideológica). A área urbana revela-se por meio do sujeito discursivo como um lugar que atrai as pessoas iludindo-as com promessas de melhoria de vida e depois acaba descartando-as (temos aqui outra Formação Ideológica). Nelo é um bom exemplo disso, pois partiu para São Paulo em busca de oportunidades e, no entanto, acabou fracassando, retornando a Junco sem nada. Daí, o sonho do lugar, de Junco, também morreu, já que Nelo, a esperança viva que o povo alimentava em relação ao sucesso que a cidade reservava a todos que nela fossem se aventurar provou o contrário. Nesse momento da narrativa, o sujeito de discurso nos mostra que aquela visão idealizada que se construiu a respeito da cidade precisa ser repensada.

Vimos, até aqui, como a inscrição socioideológica do sujeito de discurso interfere na produção de sentidos. Assim, dá-se a produção de determinados discursos e não outros. A partir daí, tomamos consciência de que a ideologia produz seus efeitos se materializando nos discursos. Desta forma, cabe dizer que as Formações Ideológicas são constituintes de qualquer discurso que, por sua vez, está inscrito em determinada FD. 
Considerando que o sujeito é afetado pela ideologia, cabe destacar que o mesmo não se dá conta disso e age sob a ilusão de que é a origem de seu dizer, esquecendo, pois, que o seu discurso só faz sentido porque já existe.

Já sabemos que o que dizemos só faz sentido porque já tem sentido, que os nossos discursos não são originalmente nossos. Todo dizer, todo discurso está em relação com o "já-dito", com o "pré-construído", com uma memória discursiva e, portanto, com o interdiscurso. Na obra que aqui tomamos como objeto de análise, foi possível verificar que os discursos produzidos pelo sujeito de discurso só fazem sentido porque seus sentidos possuem uma existência histórica. Dessa forma, os discursos construídos acerca do campo e da cidade pelo sujeito de discurso na obra têm por base "jáditos" em outros lugares, momentos e por sujeitos diferentes. Vale ressaltar que tais discursos foram construídos pelo viés do esquecimento ideológico, isto é, aquele que leva o sujeito a pensar e agir como se seus dizeres não possuíssem uma existência histórica, não estivessem inscritos no interdiscurso.

\section{Considerações finais}

Na presente discussão, foi possível compreender como os discursos são construídos para produzir sentidos através de algumas noções que desenvolvemos aqui. Assim, a partir da noção de CP, compreendemos que a obra em análise aborda o momento em que o processo de migração de nordestinos para o Sul do Brasil ocorria em grande escala. Além disso, os discursos proferidos acerca da cidade e do campo revelam posições ideológicas assumidas pelo sujeito de discurso e, por isso, O cachorro e o lobo é constituído de determinados discursos e não outros. Dessa forma, o sujeito de discurso produziu determinados discursos com base em sua posição e lugar socioideológico em que se inscreve. Assim, só foi possível a produção dos discursos porque as CP permitiram a sua emergência.

Não existe discurso neutro, todo discurso tem existência em $\mathrm{CP}$ específicas e só faz sentido porque já possuem sentido, uma vez que não somos a origem do nosso dizer. Os discursos são construídos a partir de um já- 
dito e é essa preexistência mesma do dizer que permite se dizer algo. Sendo assim, todo discurso está em relação com outros discursos, produzidos em outros lugares, outra época, por sujeitos diferentes.

\section{Referências}

BAGLI, Priscilla. Rural e urbano: harmonia e conflito na cadência da contradição. In: Cidade e campo: relações e contradições entre urbano e rural. Maria Encarnação Beltrão Sposito, Arthur Magon Whitacker (Org.). 2 ed. São Paulo: Expressão Popular, 2010.

BORGES, Valdeci Rezende. História e Literatura: Algumas Considerações. Revista de Teoria da História. v, 1, n. 3, junho, 2010.

BRANDÃO, Helena H. N. Analisando o discurso. Disponível em:

http://www.museulinguaportuguesa.org.br/files/mlp/texto1.pdf. Acesso em: 19 de out. 2015.

FERNANDES, Cleudemar Alves. Análise do Discurso: Reflexões Introdutórias. 2 ed. São Carlos: Claraluz, 2007.

INDURSKY, Freda. Unicidade, desdobramento, fragmentação: a trajetória da noção de sujeito em Análise do Discurso. In: Práticas Discursivas e identitárias. Solange Mittmann, Evandra Grigoletto, Ercília Cazarin (Org.). Sujeito \& Língua. Porto Alegre: Nova Prova, PPG-Letras/UFRGS, 2008. (Col. Ensaios, 22).

LAGAZZI, Suzy. O desafio de dizer não. São Paulo: Pontes, 1988.

ORLANDI, Eni Puccinelli. Análise de Discurso: Princípios e Procedimentos. 4 ed. São Paulo: Pontes, 2002.

PÊCHEUX, Michel. Análise automática do discurso (AAD69). Trad. Eni Pulcinelli Orlandi. In: Por uma análise automática do discurso: uma introdução à obra de Michel Pêcheux. F. Gadet e T. Hak (Org.). Campinas: Ed. da UNICAMP, [1969] 1997 .

PÊCHEUX, Michel, FUCHS C. A propósito da análise automática do discurso: atualização e perspectivas (1975). In: Por uma análise automática do discurso: uma introdução à obra de Michel Pêcheux. F. Gadet e T. Hak (Org.). Campinas: Ed. da UNICAMP, 1997b. 
TORRES, Antônio. O Cachorro e o Lobo. 3 ed. Rio de Janeiro: Record, 1998. 224p.

WILLIAMS, Raymond. O campo e a cidade: na história e na literatura. Londres, 1973.

WIRTH, Louis. O urbanismo como modo de vida. Rio de Janeiro, 1938, p. 97-122.

Recebido em 10 de novembro de 2016.

Aceito em 10 de dezembro de 2016. 
